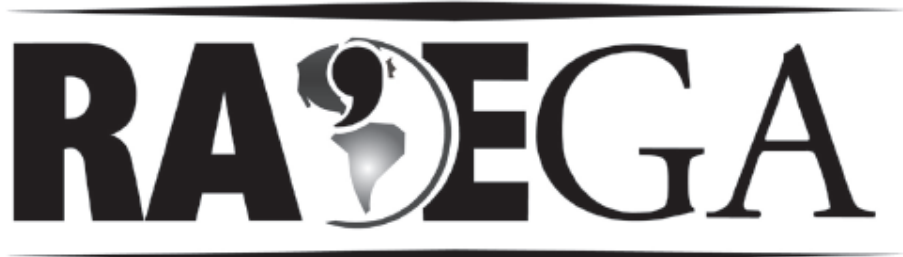

O ESPAÇO GEOGRÁFICO EM ANÁLISE

\title{
JUVENTUDES, GEOGRAFIA E RELIGIÃO: REFLEXÕES A PARTIR DAS NOÇÕES DE FORMA SIMBÓLICA E
} HABITUS

\section{YOUTH, GEOGRAPHY AND RELIGION: REFLECTIONS FROM THE NOTIONS OF SYMBOLIC FORM AND HABITUS}

\author{
Dalvani Fernandes ${ }^{2}$
}

\section{RESUMO}

Procuramos refletir nesse artigo sobre a relação entre juventudes e religião. Apresentamos algumas obras que nos dão uma noção de como o tema vem sendo trabalhado atualmente. Partindo da Geografia da Religião, propomos uma abordagem que privilegie a caráter sagrado da religião na vida dos jovens, adotando uma postura fenomenológica com base na filosofia da linguagem de Ernst Cassirer. Os conceitos que fundamentam nossa teoria são: Forma Simbólica, Habitus religioso e Espacialidades. Esse artigo é resultado das reflexões surgidas em torno da nossa pesquisa de mestrado - realizada no Programa de Pós-Graduação em Geografia da Universidade Federal do Paraná - UFPR.

Palavras-chave: Juventude; Religião; Espacialidades; Formas Simbólicas.

\footnotetext{
1 O presente artigo é uma versão revisada e ampliada de um texto já publicado no I Seminário de Pesquisa Juventudes e Cidade, 06 e 07 de outubro de 2011, Universidade Federal de Juiz de Fora.

2 Doutorando do Programa de Pós-Graduação em Geografia da Universidade Federal do Paraná - UFPR, Professor de Geografia do IFPR - Campus Curitiba, Curitiba, Paraná, Brasil. dalvani.fernandes@gmail.com
} 


\section{ABSTRACT}

We tried to contemplate in this article about the relation between youth and religion. We presented some works that give us a notion of how the theme has been worked at the moment. Leaving from Geography of Religion, we propose an approach which privileges to sacred character of the religion in the youths' life, adopting a phenomenological posture with base in the Ernst Cassirer's language philosophy. The concepts that base our theory are: Symbolic Forms, religious Habitus and Spatiality. This article is resulted of the reflections that raised around our master's degree research - that was made in the Program of Post-Graduate in Geography from Federal University of Parana.

Keywords: Youth; Religion; Spatiality; Symbolic Forms.

\section{Introdução}

A juventude vem ganhando espaço nas discussões tanto em âmbito acadêmico como nas agendas para o desenvolvimento de políticas públicas. Juventude é um conceito que pode ser desenvolvido partindo de vários pontos diferentes como: faixa etária, contingente populacional, período de transição da vida adolescente para adulta, categoria social, ou ainda uma geração. Independente da opção escolhida não se pode perder de vista à dimensão da construção sócio-histórica dessa categoria.

Para as políticas públicas juventude sempre vai corresponder com a faixa de idade, mesmo não tendo limites etários previamente definidos ${ }^{3}$. Existem ainda outras maneiras de definir o jovem. Na sociedade moderna ocidental, juventude é um período da vida que começa com as mudanças físicas da puberdade e termina, em teoria, com a inserção no mundo adulto, marcado pelo mercado de trabalho e constituição de um núcleo familiar.

Essa fase de transição não possui um tempo determinado, ela se alonga na sociedade contemporânea, comportando diferentes períodos dependendo do contexto social e da trajetória de cada indivíduo (DAYRELL, 2005). Tal linearidade do processo de transição não é a regra. As condições que demarcam começo e final da juventude são relativas a cada condição

\footnotetext{
${ }^{3}$ A faixa etária para os jovens, de acordo com a Organização das Nações Unidas (ONU), é dos 14 aos 24 anos, no entanto, a Organização Internacional da Juventude (OIJ) amplia essa faixa até os 29 anos (ABRAMO, 2005). No Brasil foi aprovado no dia 05/10/2011, o Estatuto da Juventude - com princípios e diretrizes para o Poder Público criar e organizar políticas para jovens na faixa de 15 a 29 anos.
} 
sócio-histórica, não bastando de forma isolada para caracterizar início ou fim dessa fase da vida. De acordo com CARDOZO (2007, p.02), "a perda de linearidade deste processo é um elemento que caracteriza hoje a condição juvenil".

Mesmo sendo um período da vida marcado pelo "vir-a-ser", transitando entre mundo adulto e adolescente, a juventude possui qualidades e significados próprios, expressando sua cultura no espaço das cidades, gerando grande visibilidade. Ela está sempre se construindo, se metamorfoseando ao longo dos tempos e espaços, resultando em uma grande diversidade de "ser jovem". A juventude, assim, pode ser encarada como um fenômeno plural, o que temos é uma grande variedade de "mundos" jovens, constituindo diferentes formas de juventudes, no plural, (DAYRELL, 2004); ou se preferirmos, diferentes culturas juvenis (PAIS, 2003).

Dentro desse caleidoscópio formado pelos diversos modos de "ser jovem", encontramos um fenômeno complexo com características que podem ser espacializadas, indo além do mundo da cultura, perpassando também o universo da religião, onde a juventude busca uma ligação com o sagrado refletindo em uma maneira singular de "ser jovem" na sociedade.

Nesse sentido, Novaes (2005, p.263) afirma que, acompanhando recortes como classe, gênero, raça ou cor, local de moradia, opção sexual, estilo ou gosto musical, também "a religião pode ser vista como um dos aspectos que compõem o mosaico da grande diversidade da juventude brasileira."

Observamos nessa relação religião e juventudes, uma lacuna na literatura que pode ser preenchida a partir do aporte teórico da Geografia. Nesse viés, procuramos aprofundar o debate partindo da forma simbólica religião como conformadora da objetivação da realidade dos jovens. A religião, a partir do seu discurso, fornece aos jovens subsídios para que criem um habitus religioso que Ihes garanta uma forma específica de ser no mundo, refletindo na espacialização da religião e em novas espacialidades no seu cotidiano. Buscando compreender essa realidade, construímos um aporte 
teórico partindo das formas simbólicas de Ernst Cassirer e da Geografia da Religião ${ }^{4}$.

Nesse contexto, aceitamos que a abordagem etnográfica, partindo das ideias de habitus religioso, representações e formas simbólicas, pode contribuir para entender como a juventude religiosa se relaciona com o caráter sagrado da religião. O que sugerimos com a filosofia de Cassirer é que as formas simbólicas proporcionam novos sentidos para o mundo, dando a impressão para o sujeito que os vive que um novo espaço foi construído. Assim, a aplicação das verdades religiosas para compreensão do mundo cria novos espaços e espacialidades, dando ao pesquisador a possibilidade de "geografizar" o mundo dos sentidos. Essa Geografia só é possível se levarmos em consideração que a articulação entre discurso religioso (universo simbólico) e mundo empírico (universo dos fatos) é feita através da ação das formas simbólicas.

Antes de mergulharmos nesse arcabouço teórico, entendemos ser importante apresentarmos o estado da arte envolvendo a relação entre jovens e religião, bem como observarmos como esse tema vem sendo abordado pelas Ciências Sociais, em especial a Geografia.

\section{Religião e Juventudes}

Juntamente com a modernidade e a racionalização científica houve um período de crescimento da secularização. "Houve um tempo em que os descrentes, sem amor a Deus e sem religião, eram raros” (ALVES, 1981, p.11), tão raros que surpresos por sua descrença se escondiam. De fato, caso não se escondessem podiam perder suas vidas. No entanto, algo aconteceu e o encanto da religião foi quebrado. A religião, como forma de dar sentido a vida, divide espaço com a ciência, como forma de explicar a vida e seus fenômenos. A moral e a ética religiosa aos poucos foram sendo substituídos pela moralidade kantiana, estendida sob o manto da racionalidade. O ser humano

\footnotetext{
${ }^{4}$ Abordamos com maior profundidade a filosofia das formas simbólicas de Cassirer no trabalho "Geografia em Cassirer: perspectivas para Geografia da Religião". (FERNANDES E GIL FILHO, 2011).
} 
tornou-se a medida de si mesmo. Diante desse cenário, a questão emerge: seria então o fim da religião?

Filósofos como Marx chegaram a afirmar o fim da religião com o desenvolver histórico da sociedade, outros, como Nietzsche, já no século XIX foram além afirmando que "Deus está morto!". O interessante, diante desses fatos, é o paradoxo que entra em cena com o fenômeno da dessecularização.

Novas formas de se relacionar com o sagrado vão aparecendo, transformam-se, adaptam-se, sofrem verdadeiras metamorfoses. Alves (1981) levanta a profunda questão: haveria alguém despossuído das perguntas religiosas? Para respondê-la, temos que ter claro que a religião não se elimina com o fim dos atos sacramentais ou a ausência de lugares sagrados, do mesmo jeito que o desejo sexual não se acaba com os votos de castidade. É quando a dor bate a porta e a ciência não conforta, quando surgem questões sobre o sentido da vida e da morte que o sentimento religioso aparece. Para o autor, são as mesmas perguntas do passado, que hoje se articulam por meio de símbolos secularizados "metamorfoseiam-se os nomes. Persiste a mesma função religiosa" (1981, p.13), Alves prossegue, "a religião está mais próxima de nossa experiência pessoal do que desejamos admitir" (1981, p.14). Na mesma linha de raciocínio expressa Berger (2000, p.19), "o impulso religioso, a busca de um sentido que transcenda o espaço limitado da existência empírica neste mundo, tem sido uma característica perene da humanidade". A religião está mais viva que nunca.

Nesse sentido, concordamos com a tese de Cardozo (2010) de que a religiosidade se constitui numa dimensão fundamental na vida dos jovens, sendo que o vínculo às identidades religiosas são pilares basilares na construção da identidade social do jovem, bem como da sua cosmovisão. $\mathrm{O}$ autor explica que o jovem brasileiro vem criando formas inovadoras de expressar e se relacionar com o sagrado, realizando uma experiência da sua religiosidade dentro ou fora das instituições religiosas ${ }^{5}$.

\footnotetext{
${ }^{5}$ A juventude organizada a partir da religião, mas desvinculada das instituições religiosas, é abordada por Cardoso (2011), O referido autor se utiliza da expressão Underground Cristão para definir os jovens cristãos que constroem redes de sociabilidade em torno de "microcomunidades emocionais voltadas para os mundos artísticos marcadamente 'juvenis' (heavy metal, punk/straight edge, hip hop, emo, indie, gótico) (p.17).
} 
Partindo do conhecimento de Igrejas neopentecostais, como a Bola de Neve Church, Cardozo (2010) entende que são adaptações do discurso religioso para melhor atender a uma parcela jovem da sociedade. Tais Igrejas possuem uma linguagem específica com gírias e até mesmo alguns "palavrões". Em Igrejas mais conservadoras como a Católica Apostólica Romana é possível vermos milhares de jovens reunidos durante o período de carnaval em acampamentos de oração, tais momentos "arrebatam centenas, milhares de jovens sedentos por uma experiência, por emoção", afirma o autor (2010, p.77). Observamos atualmente um crescente número de jovens pastores e padres buscando evangelizar outros jovens, emerge atualmente "uma grande onda de juvenilização das religiões" (CARDOZO, 2010, p.78).

Tal fenômeno é natural tendo em vista a necessidade de renovação dos fiéis de geração para geração ${ }^{6}$ dentro das religiões. $O$ que temos de novo são as novas estratégias pelas quais os jovens são disputados pelas diferentes religiões, ou profissões de fé (Igrejas) dentro da mesma visão religiosa, algo muito comum dentro do Cristianismo, por exemplo.

\section{Juventudes e Religião}

De acordo com o IBGE (2010) mais de 37 milhões de brasileiros estão na faixa de etária dos 14 aos 24 anos, correspondendo a 19,7\% do total de habitantes. Um número que nos impressiona e traz muitas perguntas sobre nossas "juventudes".

A pesquisa Juventude Brasileira e Democracia, realizada em 2004 pelo IBASE/POLIS (2005), procurou desvendar algumas respostas. Abarcou oito regiões metropolitanas brasileiras totalizando mais de 8.000 jovens entrevistados, apresentando como resultado um novo perfil religioso da juventude brasileira.

A pesquisa revelou que apesar da maioria de jovens no país ainda ser de Católicos Apostólicos Romanos (54,9\%), é progressivo o crescimento da juventude evangélica $(21,4 \%)$ - nesse total de evangélicos somam-se

\footnotetext{
${ }^{6}$ A noção de "geração" remete à idéia de similaridade de experiências entre indivíduos que nasceram em um mesmo momento histórico. (ABRAMO, 1994)
} 
protestantes históricos, pentecostais e neopentecostais. Apenas $2 \%$ dos jovens se identificaram como ateus, indicando que o cenário religioso da juventude contemporânea apresenta mais jovens "sem religião" (14,3\%) que as gerações anteriores. Esse panorama nos leva a refletir sobre o "espírito da época", onde jovens são chamados a participar de um campo religioso mais plural e competitivo, resultando daí adesões simultâneas a diversos sistemas de crença ${ }^{7}$. (NOVAES, 2004)

Outro ponto interessante revelado pela pesquisa foi 0 fato de que $28,5 \%$ dos jovens revelaram possuir ligação com algum tipo de espaço de sociabilidade. A religião aparece como espaço de sociabilidade privilegiado, pois a pesquisa informa que desse total, $42,5 \%$ afirmaram reunir-se em torno de atividades religiosas.

Novas contribuições são dadas pela pesquisa "Perfil da Juventude Brasileira" $^{\prime \prime}$, realizada no início de 2004, que ouviu 3.501 jovens de 15 a 24 anos de várias classes sociais e localidades geográficas, os dados sobre religião logo chamam a atenção. Partindo dos resultados desse trabalho Novaes (2005, p.263-264) informa que, "a religião ocupou um lugar surpreendente entre os assuntos que os jovens gostariam de discutir não só com os pais, mas também com os amigos e com a sociedade." Entre as coisas que eles mais gostam de fazer nos finais de semana, ganha destaque a alternativa "ir à missa/igreja e culto". Outro ponto interessante levantado por esses jovens diz respeito aos valores de uma sociedade ideal, como compreender que um número significativo de jovens (em resposta única) destacasse o "temor a Deus" como valor mais importante (?), questiona a autora.

Em relação à diversidade de possibilidades de interação com 0 sagrado, Novaes (2005) explica que os jovens de hoje tem muito mais acesso as religiões, para ter acesso a uma bíblia, por exemplo, basta ir a uma livraria, os versículos são cantados em letras de rap aparecem escritos em outdoors no

\footnotetext{
7 Para Novaes (2004) o fato de "ser católico" deixar de ser um requisito social obrigatório, pode indicar que os "sem religião" estejam participando de movimentos religiosos como o Espírita, Candomblé e Umbanda.

${ }^{8}$ Para maiores informações recomendamos a leitura de Abramo e Branco (2005).
} 
centro das cidades, nos muros das favelas e periferias, não precisam se submeter à autoridade dos mediadores religiosos tradicionais. A TV permite ter acesso a programas espíritas, a rituais de lgrejas pentecostais. Nas lojas de produtos esotéricos, nas feiras, no rádio já encontram ofertas de "orientalização" das crenças ocidentais convivendo com uma difusa negação do dualismo cristão.

Essa relação, juventudes e religião, pode se configurar em formas "híbridas" - como os "Carecas de Cristo" e as tribos do Underground Cristão relatados por Costa (2004), demonstrando o envolvimento de jovens paulistas membros de grupos skinheads, com Igrejas Neopentecostais. Segundo a autora, no fim da década de 1980 e início de 1990, as Igrejas começaram a assumir um papel mais liberal, principalmente no caso das neopentecostais. Antes disso, os jovens que entravam para Igreja "buscavam apoio e proteção para enfrentarem as agruras do cotidiano e as incertezas da vida, no interior dos templos. Só que, ao fazê-lo, deixavam de ser um careca ou um punk" (COSTA, 2004, p.49). A partir da flexibilização dessas Igrejas, os jovens não precisam abdicar do seu grupo para freqüentá-la, entretanto, necessitavam se adequar. Podem manter o visual, contudo, precisam deixar de lado a violência, rixas e atitudes intolerantes.

Encontramos na antropologia outro exemplo de hibridismo. Cruz (2000) utilizando elementos "socioestéticos" diferencia grupos juvenis no México. Dentre os grupos identificados, destaca-se os jovens "Raztecas", segundo a autora, esse grupo faz uma miscigenação interessante entre elementos do sagrado das religiões dos seus antepassados, os Astecas, e da cultura negra, representada pela religião Rastafari.

A relação entre jovens e Igrejas mais tradicionais é percebida por Carrano (2002, p.82), ao descrever a juventude que freqüenta a mancha de lazer da rua Coronel Carvalho, em Angra dos Reis. O autor relata que para a "mocidade evangélica" a cidade se encontra dividida entre espaços de salvação e perdição. Essa diferenciação espacial permite construir diferenciações territoriais de onde se pode, ou não, circular. Os espaços de 
perdição, ocupados pelo demônio, são alvos de evangelização, pois "ainda não teriam encontrado a verdade, expressa na palavra de Jesus."

No próximo tópico abordaremos alguns trabalhos que tratam da questão das juventudes a partir da perspectiva geográfica, procurando entender como a Geografia pode contribuir nesse debate.

\section{Geografia e Juventudes}

No campo da Geografia, Peluso e Tormim (2005) trabalharam com o Movimento de Jovens da Igreja Católica, no Distrito Federal, observando as mudanças de identidade e de comportamento entre jovens sujeitos a situações de marginalidade e violência, procurando identificar como o pertencimento a um grupo religioso influencia as visões de mundo e de si mesmos. Segundo as autoras, "a religião atravessa o discurso dos jovens e estabelece os parâmetros para que cada um fale de si próprio, dos outros e do mundo" (2005, p.129). Concluem dizendo que as identidades emergem das relações sociais e a identidade religiosa - ao dar sentido a estas relações - permite aos jovens ordenar, apresentar motivos e desejar realidades alternativas.

Hopkins (2007) sugere que os geógrafos deveriam investir mais esforços em pesquisas que envolvam debates em torno do racismo, juventude, religião e masculinidades. Citando o trabalho de Dwyer (2000), Hopkins faz referência à forma de como os jovens muçulmanos do sexo masculino usam a religião para justificar sua autoridade, reforçando gêneros patriarcais locais; para o autor essa é apenas uma, das poucas referências sobre os jovens homens religiosos e racializados na Geografia Humana. Para Hopkins o encontro da Geografia com a Religião é algo que aconteceu em poucas ocasiões na Geografia Humana, no entanto, já se apresentam sinais de que isso esteja mudando.

Lily Kong (2001, p.211) declara sua insatisfação pela forma que a religião é incompreendida e "rotulada como esgotada, supostamente atraindo poucos pensadores". A religião, nesse cenário, é com frequência deixada em segundo plano, ou combinada e absorvida pelo estudo de raça. 
$\mathrm{Na}$ literatura estrangeira, observamos que há uma Geografia da Criança e do Jovem florescendo (SKELTON e VALENTINE, 1998; MATTHEWS e LIMB, 1999; AITKEN, 2001; HOLLOWAY e VALINS, 2002), no entanto, aponta Hopkins (2007), ainda são poucas as investigações entre os jovens que estão no limite entre infância e idade adulta, aqueles na faixa dos 16 aos 25 anos; e menos ainda pesquisas que procuram discutir a relação juventude, religião e gênero.

Hopkins (et al, 2011), procurando explorar esse campo, analisa a influência intergeracional na construção de identidades religiosas em jovens cristãos escoceses, revelando conflitos e o complexo modo de como os jovens são, ou não são, influenciados pelas relações intergeracionais. Seus apontamentos demonstram que locais como a casa dos avós, os trajetos até a Igreja, os grupos de jovens, as práticas e relações com a cultura popular, tudo apresenta influências significantes na vida e na religiosidade dos jovens. Os autores incentivam novas pesquisas afirmando que os "geógrafos da religião e juventude podem focalizar mais de perto as diversas espacialidades e articulações da religiosidade juvenil e das ralações sociais inerentes a elas" (2011, p.326).

Ao observarmos pesquisas sobre juventudes a partir do olhar geográfico notamos uma preocupação, a princípio, com o papel do contexto socioespacial na construção de formas específicas de vivências juvenis, articulando conceitos como os de território e territorialidade juvenil. Há exemplo, citamos as contribuições de Turra Neto (2004, 2008); Fernandes e Turra Neto (2009) e Fernandes et al (2007). Nesse sentido, o lugar dos/as jovens na cidade representa possibilidades e limites para suas vivências; a circulação pelo espaço da cidade permite com que inúmeras conexões sejam possíveis, refletindo assim em uma incrível diversidade de "culturas juvenis". Toda essa diversidade cultural juvenil se reflete em diferentes formas de apropriação do espaço urbano, imprimindo nele marcas por meio de territorialidades juvenis e delimitando diferentes territórios; indícios de complexos processos de tensão e negociação por espaço. 
A análise da literatura voltada à Sociologia da Juventude nos revela possibilidades abertas para uma abordagem geográfica, pois conceitos como lugar, espaço, cidade e globalização são também constantemente acionados por diferentes especialistas de diferentes campos do saber que discutem 0 fenômeno juvenil.

Para Cardoso e Turra Neto (2011), o diálogo no Brasil entre os estudos de juventudes e a Geografia ainda está em fase de incubação, sem teorias sistematizadas ou diálogos interdisciplinares. Reflexo disso é a crescente preocupação com a espacialidade das culturas juvenis, expressos nos trabalhos de Sociologia da Juventude, que, no entanto, não apresentam precisão conceitual por estarem distantes de uma aproximação teórica com a ciência geográfica. Isso não significa que o espaço, enquanto objeto, é algo exclusivo da Geografia, mas é preciso reconhecer que ela é a ciência que se preocupa teórica e metodologicamente sobre as abordagens do espaço. Os autores concluem esse pensamento afirmando que,

Um debate sobre a espacialidade da condição juvenil, que não estabelece interlocução com a Geografia, pode deixar de explorar todas as possibilidades que a abordagem espacial oferece para o desvendamento da dinâmica das juventudes, contemporâneas ou não. Essa limitação das pesquisas em outros campos disciplinares, não significa, contudo, que elas devem ser rejeitadas em sua totalidade. Pelo contrário, são trabalhos que contribuem imensamente para o debate sobre juventudes e que apresentam, inclusive, questões importantes para que a própria Geografia possa pensar as espacialidades humanas atuais e repensar seus próprios conceitos. (CARDOSO E TURRA NETO, 2011, p.11)

Para os autores, a Sociologia da Juventude, que já havia realizado uma "virada cultural" ao privilegiar aspectos culturais nas formas de "ser jovem", agora encontra-se na eminência de conduzir também uma "virada espacial". Isso repercute em um momento onde a Geografia tem a possibilidade de ensinar e de aprender com o estudo das juventudes.

Como podemos observar, passando pela Sociologia, Antropologia e Geografia Humana e Social, a relação entre religião e juventudes se caracteriza por ser um fenômeno complexo e diversificado. Essa significativa 
parcela jovem da sociedade que se relaciona com algum tipo de religiosidade, principalmente as ligadas a instituições religiosas, faz emergir uma nova forma de participação social, que deveria repercutir no entendimento e compreensão do cenário da juventude brasileira.

\section{Contribuições da Geografia da Religião para abordagem da temática "juventudes"}

Depois desse tour d'horizon pelos trabalhos envolvendo o debate juventudes e religião, procuramos então contribuir com essa literatura apontando possibilidades de análise partindo especialmente da Geografia da Religião. Acreditamos que a teoria elaborada sob essa ótica traz novas perspectivas sobre as maneiras de ser jovem hoje, especialmente em relação à forma que os jovens "constroem seus mundos".

Observamos que a literatura que trata da relação juventudes e religião destaca conceitos como: identidade juvenil, sociabilidade, grupos culturais e "hibridismos" (envolvendo religião e outras redes simbólicas). Nesse viés, a religião aparece como cultura, um lócus da sociabilidade juvenil como muitos outros. A Igreja é local de reunião, e a comunidade religiosa o grupo de "iguais" onde o jovem se envolve para construir sua identidade, marcando fronteiras com demais grupos. Esse olhar para com a religião possibilita inúmeras análises da vida social juvenil, no entanto, deixa de lado o caráter transcendental e sagrado do fenômeno religioso, que preenche a vida de seus fiéis com respostas existenciais e um ethos que orienta a vida do/a jovem crente. É nesse ponto que pretendemos contribuir. Notamos que mesmo diante do cenário de "juvenelização da religião" e "hibridismos culturais", é possível percebermos 0 crescimento de movimentos religiosos conservadores/tradicionais como as Igrejas Pentecostais ${ }^{9}$, tendo como exemplo a presença secular no Brasil da Igreja Assembléia de Deus. Perguntamo-nos então, o que os jovens buscam nessas Igrejas? Qual o

\footnotetext{
9 De forma genérica poderíamos caracterizar o movimento pentecostal pela sua ortodoxia bíblica, moralidade religiosa, glossolalia (fala em línguas estranhas), ênfase na cura espiritual e dons do Espírito Santo.
} 
sentido da religião na vida deles/as?

Entendemos que para responder a tais questões precisamos mergulhar para além das pesquisas que citamos anteriormente, é preciso entender o mundo do jovem partindo da religião, entendendo a religião como um "mundo de palavras": um universo que o jovem habita e através dele preenche de sentido a sua vida e tudo a sua volta. É com esse sentimento que buscamos apresentar as Formas Simbólicas como caminho viável para algumas respostas.

\section{Religião - uma Forma Simbólica}

É nesse terreno que nos debruçamos, procurando entender como a religião oferece possibilidades para um "modo de ser" da juventude. Entendemos que os trabalhos que encontramos e abordam essa temática possuem como objetivo principal apresentar a religião como uma dimensão social na vida dos jovens. Nossa intenção, por sua vez, é apresentar um método que possa abranger a religião a partir do seu caráter sagrado ${ }^{10}$, buscando compreender o sentido religioso que plasma a realidade dos jovens. Para isso uma das possibilidades seria partir da linguagem, isto é, do discurso que a religião oferece como "matéria prima" para construção do "mundo da juventude religiosa".

Utilizamo-nos do aparato conceitual da Geografia da Religião, colocando como conceitos centrais: espaço e espacialidade. Partindo da filosofia da linguagem, de Ernst Cassirer (1874-1945), construímos nossa leitura sobre a religião. O pensador em questão sugere realizarmos uma "revolução copernicana” (KANT, 1999 [1787]) na Geografia, isto é, trocarmos do centro das análises o universo dos fatos, pelo universo simbólico do "sujeitoobjeto".

Para isso, passamos a pensar o espaço através da atuação das Formas Simbólicas, conceito que pode ser entendido como: energia do espírito, onde um conteúdo espiritual do significado está vinculado a um signo sensível

\footnotetext{
${ }^{10} \mathrm{O}$ fenômeno religioso emergirá como tal, somente "com a condição de ser apreendido dentro de sua própria realidade, isto é, de ser estudado à escala religiosa”. (ELIADE, 1977)
} 
concreto atribuído interiormente (CASSIRER, 2001 [1923]). Em outras palavras, são os aparatos artificiais da nossa consciência (espírito lingüístico) que projetam o conhecimento sobre o mundo (através da ação das formas simbólicas: mito, arte, ciência, religião) conformando (dando sentido) ao mundo sensível (empírico). A imagem abaixo procura expressar esse ideia:

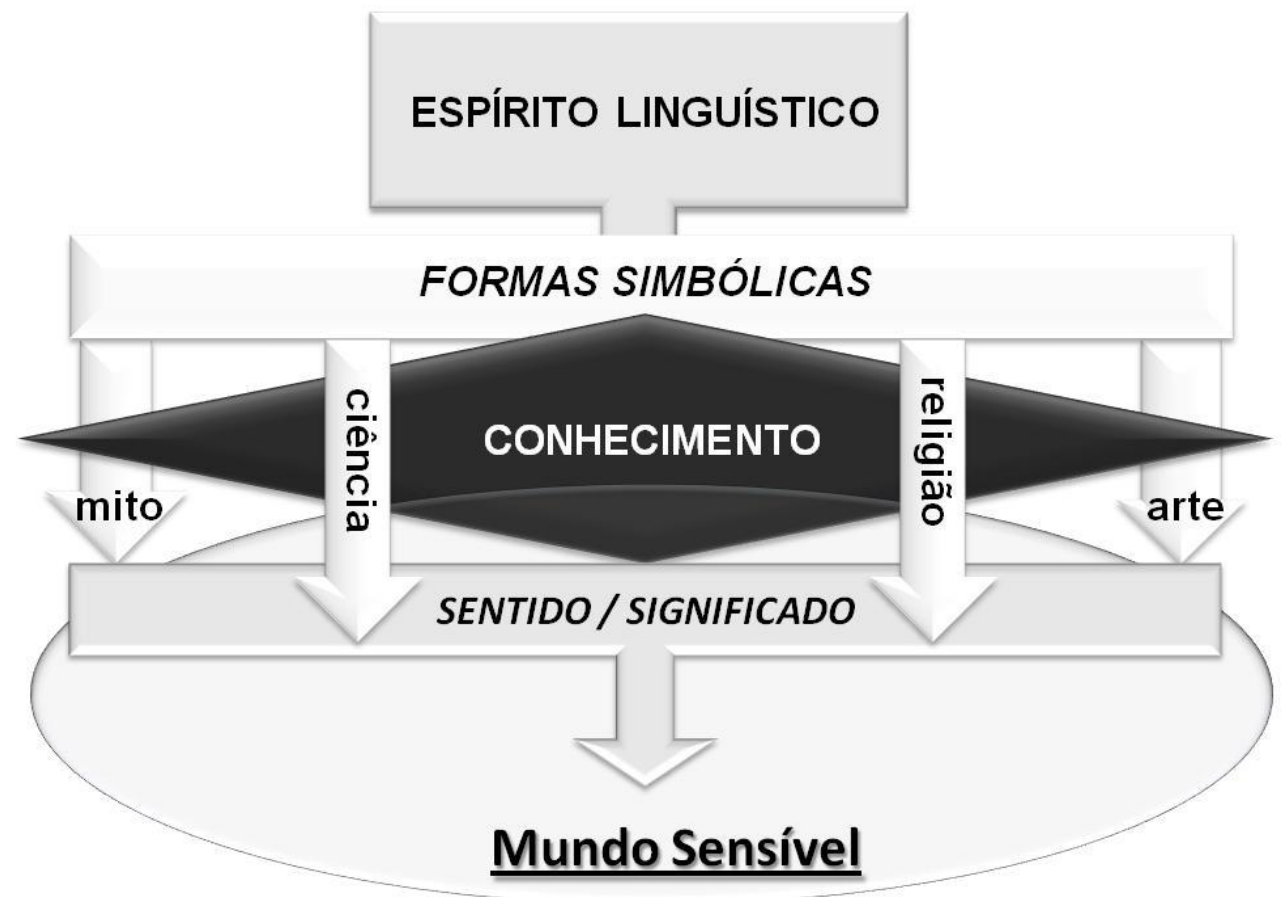

Figura 01 - Ação das Formas Simbólicas de Ernst Cassirer

Fonte: CASSIRER, 2001 [1923]; 2005a [1942]; 2005b [1944].

Org: FERNANDES, D. 2012.

O conceito de Formas Simbólicas pode ser utilizado na tarefa de espacialização da religião. Para Cassirer, somos Homens simbólicos em nossa forma de pensar, através da linguagem construímos um mundo de símbolos um mundo cultural - é nesse mundo "artificial" no qual o ser humano vive. Existem vários "mundos" que são conformados a partir de diferentes perspectivas: mito, arte, religião, ciência, entre outros (CASSIRER, 2005b [1944]). A Geografia, partindo do espaço da cultura, analisa os espaços de ação formados por essas Formas Simbólicas; daí surge à possibilidade de analise do espaço de ação do "mundo jovem", formado a partir da Forma Simbólica religião. 
Viver em um mundo conformado pela Forma Simbólica significa viver a realidade plasmada pelo sentido instituído por um sistema simbólico (religião, ciência, mito, artes, etc). Para Cassirer, o Homem, vivendo em um sistema simbólico "não vive apenas em uma realidade mais ampla; vive, pode-se dizer em uma nova dimensão da realidade" (2005b [1944], p.48). Não se encontra mais em um universo físico, agora vive em um universo simbólico, num mundo cultural construído pela linguagem ${ }^{11}$, mito, arte, ciência e religião.

\section{Juventude Simbólica}

Temos assim, a partir do conceito de Homem simbólico expresso por Cassirer, a possibilidade de chegarmos a uma juventude simbólica. Juventude que imerge em mundos culturais constituídos de teias lingüísticas, símbolos, práticas e cosmovisão. A religião surge, desse modo, como mais que uma possibilidade de identidade e integração ao mundo social, ela é a própria matéria prima na qual os/as jovens irão plasmar sentido a sua realidade. Essa afirmação não significa que o/a jovem viverá dentro de um sistema religioso fechado, mas antes que o discurso proferido pela sua religião é quem dará o "norte" para sua orientação na vida cotidiana. E isso se reflete em suas práticas sociais, trajetos pela cidade, escolhas políticas e em alguns casos afetivas. Assim, estamos dizendo que para um jovem religioso praticante, sua religião está impressa nas suas espacialidades.

Falar em espacialidade é dizer que há uma dimensão no fenômeno que se espacializa, não sendo necessariamente uma manifestação material. A ideia de espacialidade parte das articulações presentes no espaço sagrado (GIL FILHO, 2007; 2008). As espacialidades constroem as articulações no interior do espaço sagrado, dando sentido ao ser religioso. Tais espacialidades afirmam a articulação estrutural entre o espaço de expressão concreto e o espaço das representações - universo dos fatos e universo simbólico.

Procurando a melhor maneira de compreender esse "mundo simbólico", trazemos, como auxílio as ideias de habitus religioso e representação. Ambos

\footnotetext{
${ }^{11}$ LINGUAGEM, sprache em alemão, é uma palavra que também significa LíNGUA (idioma).
} 
os conceitos nos forneceram um "norte teórico", sobre o que observar estando em campo.

\section{Habitus Religioso}

Habitus é um conceito antigo, recuperado por Pierre Bourdieu (1998 [1974]) e trabalhado principalmente pela sociologia. A obra de Bourdieu pode ser entendida como uma teoria da prática a partir de estruturas sociais fundamentada em conceitos-chave, tais como: habitus, campo e capital. Suas heranças intelectuais são variadas, segundo Thiry-Cherques (2006, p.28):

A formação filosófica, a prática etnológica e a da posterior
dedicação à sociologia ancoram Bourdieu à filosofia das
ciências, na tradição de Bachelard [...], ao pensamento de
Cassirer [...], tanto no que se refere à sua filosofia das
formas simbólicas, como à sua concepção relacional do
conhecimento, e á fenomenologia de Husserl e Merleau-
Ponty; trinômio ao qual ele une o modelo estruturalista de Lévi-
Strauss. Mas as suas fontes se estendem ao marxismo e ao
diálogo intelectual com contemporâneos, como Althusser,
Habermas e Foucault. (grifo nosso)

Para o autor em foco, a postura de Bourdieu se coloca a meia distância entre o subjetivismo, que privilegia a gênese social das condutas individuais, e o estruturalismo, que não leva em consideração a dinâmica histórica e as determinações individuais. Ortiz (1994) afirma que é complicado situar Bourdieu na corrente de pensamento sociológico moderno, pois sua obra é difícil de ser situada em relação a uma escola, posto que seu pensamento é profundamente original.

Habitus é uma ideia filosófica antiga, suas raízes encontram-se na noção aristotélica de hexis, construída na sua doutrina sobre a virtude, "significando um estado adquirido e firmemente estabelecido do caráter moral que orienta os nossos sentimentos e desejos numa situação e, como tal, a nossa conduta". Foi na Escolástica medieval onde o termo foi retrabalhado e traduzido para o latim como habitus (particípio passado do verbo habere, ter ou possuir) por Tomás de Aquino. Esse termo foi utilizado por sociólogos da geração clássica como Durkheim, Weber e Veblen. Na fenomenologia, aparece de forma mais proeminente nos escritos de Husserl "que designava por habitus a conduta 
mental entre experiências passadas e ações vindouras"; também utilizava o termo como cognato para habitualität (conhecimento habitual). O termo habitus também figura de passagem por alguns estudantes de Husserl como Norbert Elias, que fala de "habitus psíquico das pessoas 'civilizadas"' (WACQUANT, 2007, p.05-6).

Bourdieu, retomando esse conceito, sugere uma renovação dessa ideia de modo que seja aplicada em termos práticos pela sociologia, dessa forma 0 habitus para ele,

é uma noção mediadora que ajuda a romper com a dualidade de senso comum entre indivíduo e sociedade ao captar "a interiorização da exterioridade e a exteriorização da interioridade", ou seja, o modo como a sociedade se torna depositada nas pessoas sob a forma de disposições duráveis, ou capacidades treinadas e propensões estruturadas para pensar, sentir e agir de modos determinados, que então as guiam nas suas respostas criativas aos constrangimentos e solicitações do seu meio social existente. (WACQUANT, 2007, p.06)

O habitus pode ser compreendido como a introspecção de um mundo; assim, como um capital cultural, é passado de geração para geração, é produzido e transformado, "produz história na base da história", desta forma, "assegura que a permanência no interior da mudança faça do agente individual um mundo no interior do mundo" (BOURDIEU apud WACQUANT, 2007, p.08).

Para Bourdieu, os indivíduos criam o mundo social através de instrumentos incorporados de construção cognitiva, no entanto, diferente da posição encontrada em Cassirer, estes instrumentos cognitivos são entendidos como resultado do mundo social. Em outras palavras, para Cassirer é a consciência que gera a vida, em Bourdieu é a sociedade que gera os mecanismos da consciência que, por conseguinte, resultam em um habitus social.

O conceito que apresentamos se mostra como uma ferramenta importante para a análise de atitudes subjetivas que são capazes de estruturar as representações e a geração de novas práticas. É, nesse sentido, um recurso mediador entre os indivíduos e as estruturas. Para nosso estudo, pensamos 
nesse termo enquanto mediador dos/as jovens e a religião representada pelo seu discurso.

Setton (2009) nos aproxima de Lahire ${ }^{12}$, estudioso de Bourdieu. Para este pensador não se pode pensar o indivíduo da atualidade sendo regido por um único princípio de conduta. Hoje o que se percebe são jovens socializados em uma multiplicidade de princípios, essa realidade poria em xeque a teoria do habitus. Para Lahire, os indivíduos não agiriam o tempo todo de maneira coerente a partir de um sistema coerente e único. De acordo com Setton (2009, p.299), "apoiado no conceito de habitus, Lahire afirma que Bourdieu constrói um homem perfeito, enquanto a realidade demonstra ser o indivíduo altamente complexo".

Transportando o problema para esfera da filosofia de Cassirer nos deparamos com uma realidade que poderia ser formada a partir de diferentes formas simbólicas. Fernandes (2006) analisou a coexistência de diferentes formas de compreensão de mundo, a partir das formas simbólicas, mito, religião, ciência. Notou que o pluralismo epistemológico desencadearia contradições culturais, uma vez que cada forma simbólica se julga portadora da verdade. Entendemos que essa é uma questão interessante para ser pensada, no entanto, dentro dos limites da nossa proposta de pesquisa o que nos interessa de modo mais direto é a forma simbólica religião.

Enquanto forma simbólica, a religião estrutura a experiência e a expressa no mundo através das práticas sociais. Sendo a religião uma autoridade permeada pelo sagrado, ela é legítima. Por meio de suas doutrinas ela redimensiona e submete as tendências do mundo natural e social. Através da religião o espaço e as relações socioespaciais ganham sentido. A forma simbólica projeta o conhecimento religioso sobre o mundo, o espaço de ação do Homem religioso transforma-se no seu mundo de significados com suas leis e práticas específicas.

A consciência determina a vida. O poder religioso pode ser utilizado como poder de transformação das representações, disso resultam as práticas

\footnotetext{
${ }^{12}$ Bernard Lahire é atualmente professor da École Normale Superieure Lettres et Sciences Humaines e diretor do grupo de pesquisa sobre socialização no Centre National de la Recherche Scientifique (CNRS), na Universidade Lumière, Lyon 2, França. Lahire se considera um admirador e, ao mesmo tempo, grande crítico da obra de Bourdieu.
} 
dos leigos como um novo habitus, impresso pela gestão dos bens religiosos "como base no pensamento, ação e percepção, segundo as normas de determinada representação religiosa do mundo" (GIL FILHO, 2008, p.53).

O habitus, como queremos expressá-lo aqui, é um conceito híbrido, nasce da dialética que envolve as estruturas estruturantes (discurso religioso) e as estruturas estruturadas (instituição religiosa). Visto assim, acreditamos que - habitus religioso pode nos ajudar a compreender a dinâmica e as negociações presentes na conformação da realidade a partir da forma simbólica religião, uma vez que entendemos que a forma simbólica pode ser concebida como estruturante da realidade, e que suas projeções podem vir a conflitarem com realidades já estruturadas, resultando daí conflitos e negociações para se chegar ao modelo possível de ordem de mundo.

O esquema abaixo nos ajuda a entender como o discurso religioso se projeta no espaço através do habitus:

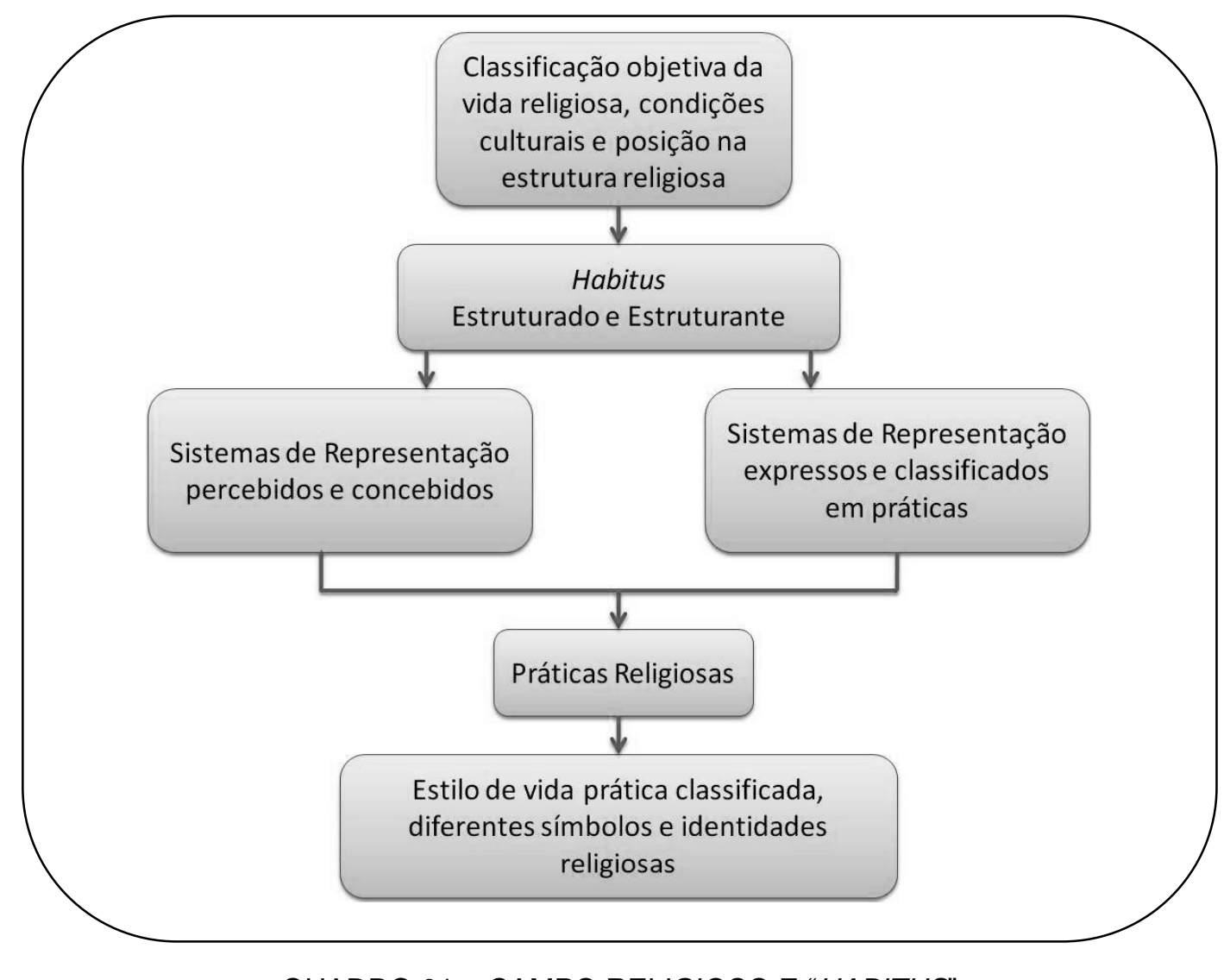

QUADRO 01 - CAMPO RELIGIOSO E "HABITUS"

Fonte: GIL FILHO, 2008, p.54.

Org: FERNANDES, D., 2011. 
Através das representações expressas pelas práticas sociais, torna-se possível "a identificação e a classificação de práticas religiosas em diferentes contextos culturais e diferentes sistemas simbólicos incorporados a uma identidade religiosa específica", é nesse viés que "o habitus religioso permite identificar uma característica específica do modo de vida" (GIL FILHO, 2008, p.55).

Para Gil Filho (2005, p.52), esse saber é a religião enquanto um sistema de símbolos sendo aplicada, uma visão de mundo a partir da linguagem expressa pela religião. Linguagem, nesse sentido, é sinônimo de representação, pois "a linguagem como função do pensamento reapresenta o mundo concreto imediato como outro, um mundo de re-significações".

A religião entendida como forma simbólica oferece uma possibilidade do Homem em criar representações para entender o mundo, dando sentido ao universo empírico através da força do sagrado. O resgate do sagrado é a tentativa de encontrar o âmago da experiência religiosa. Em que pesem todas as restrições sofridas pela experiência religiosa em várias culturas, o sagrado se impõe como base fundamental da qualidade reconhecível do fenômeno religioso. Nesse sentido, as religiões se apresentam como modalidades do sagrado que se revelam em tramas históricas e geográficas. (GIL FILHO, 2008)

Dessa forma, analisar o habitus religioso é olhar as práticas sociais e espaciais que estão conectadas as representações (discurso), é entender a religião enquanto forma simbólica (universo dos fatos + universo simbólico). As práticas religiosas seriam, assim, a ação da forma simbólica expressa na vida do fiel. O capital religioso, emanando seu poder simbólico (BOURDIEU, 2008), estaria inserido na vida do individuo na medida em que ele/ela utiliza as representações propostas pela religião para dar sentido ao mundo. Através dessas características daríamos forma ao invisível, a religião mostraria seus efeitos, permitindo com isso que esse fenômeno seja mais bem compreendido na vida da juventude. 


\section{Últimas considerações - a religião "faz" sentido: sociabilidade juvenil evangélica}

Acreditamos que essa abordagem facilita o vislumbre de possibilidades para delinear as práticas sociais juvenis que partem da experiência do sagrado, isto é, da forma simbólica religião (GIL FILHO, 2008). Por esse viés a Geografia pode contribuir com a sociologia da juventude, refletindo sobre a dimensão da espacialização da religião na vida do/a jovem.

Partimos da hipótese de que o habitus religioso praticado pelos/as jovens da Igreja resulta em uma maneira específica de "ser jovem" no mundo. Essa característica do/a jovem religioso resulta em espacialidades particulares, que podem ser entendidas a partir do discurso religioso que ele/ela professa. A religião na vida do/a jovem possibilita que se alcance um sentido para sua existência, nesse viés, a religião "faz" sentido, isto é, gera um sentido, plasmando a realidade daquele que professa a fé.

Pensamos que a forma simbólica religião pode criar laços de intersubjetividade entre os/as jovens, isto é, compartilham o mesmo discurso, permitindo que um universo simbólico em comum seja estabelecido entre eles/elas. Segundo Pais (2003), os amigos que fazem parte do grupo constituem o "espelho de sua própria identidade", a partir dele fixam suas semelhanças e diferenças em relação ao outro.

Dayrell (2006) evidencia em sua pesquisa que integrar um grupo cultural na adolescência pode significar certo ritual de passagem para a juventude, o que coincide com a ampliação de experiência de vida, pois quando muitos começam a trabalhar, passam a ter maior autonomia para sair de casa à noite, ou seja, buscam um sentido para a existência individual. É um momento próprio de experimentação e descobertas, é quando se efetivam no exercício de escolhas. Nesse processo, a turma de amigos tem papel fundamental, é onde "trocam ideias", buscam formas de se afirmar diante do mundo adulto, criando um "nó" distintivo.

(...) os grupos tendem a funcionar como uma referência para a escolha dos amigos, bem como das formas de ocupação do tempo livre. (...) É manifesto que, para esses jovens, o lugar em que se vive não aparece apenas como espaço funcional de 
residência ou de socialização, mas principalmente como espaço de interações afetivas e simbólicas, carregado de sentidos. (DAYRELL, 2006, p.12-13)

Pais (2003) nos lembra que as culturas juvenis, além de suas dimensões socialmente construídas, possuem também uma configuração espacial. A relação que se forma em torno dos grupos é de intimidade, tanto que no caso do grupo pesquisado por Dayrell eles se autodenominaram "família", na qual predomina o princípio das relações não hierárquicas. "O grupo aparece como espaço privilegiado de investimento emocional e de construção de relações de confiança, mais do que a linguagem cultural em si mesma” (2006, p.14). No entanto, alerta o autor, uma vez existindo regras, quando elas são rompidas, facilmente ocorre o distanciamento, surgindo outras relações no seu lugar. Isso explica, em parte, a mobilidade de diferentes turmas ou galeras.

A discussão sobre juventude, conforme nos mostra a literatura da área (ABRAMO, 1994 e 1997; CARRANO, 2002; PAIS, 2003; DAYRELL, 2005 e 2006, para citar alguns), exige uma reflexão sobre o conceito de sociabilidade. Para esse fim, invocamos a interpretação de George Simmel (1983; 2006), para quem a sociabilidade é entendida como uma, dentre outras formas possíveis de sociação. No entanto, ela possui sua especificidade, a sociabilidade não apresenta conteúdos obrigatórios, se define como uma forma de convivência com o outro e para outro. Caracteriza-se por encontrar nela mesma seu próprio fim, é uma relação com o outro de forma desinteressada, os laços estabelecidos pelos indivíduos têm em si mesmos sua razão de ser. Partindo desse viés, Simmel (2006, p.64) descreve como a sociabilidade ganha forma:

Assim como aquilo que se pode chamar de impulso artístico retira as formas da totalidade de coisas que lhe aparecem, configurando-as em uma imagem específica e correspondente a esse impulso, o "impulso de sociabilidade", em sua pura efetividade, se desvencilha das realidades da vida social e do mero processo de sociação como valor e como facilidade, e constitui assim o que chamamos de "sociabilidade" [Geselligkeit] em sentido rigoroso. 
Quanto mais perfeita for a sociabilidade, explica Simmel (2006, p.65), mais ela adquire da realidade um "papel simbólico" que preenche a vida do indivíduo lhe oferecendo um significado. Na sociabilidade, "o falar torna-se o seu próprio fim", trocar informações não é o objetivo principal, o assunto é desculpa para estar junto. De acordo com Dayrell, a conversação assume, para os jovens, papel muito importante, tornando-se uma das motivações principais de seus encontros. "O 'trocar ideias' é de fato um exercício da razão comunicativa, ainda mais significativo quando encontram poucos espaços de diálogo além do grupo de pares". Para o autor, são esses aspectos que apontam para a natureza democrática da sociabilidade, sendo "a dimensão do compromisso e da confiança que cimenta tais relações" (DAYRELL, 2006, p.10).

A partir dos momentos de sociabilidade, os jovens partilham de símbolos específicos que expressam a pertença a um determinado grupo, uma linguagem com seus específicos usos, rituais e eventos particulares, por meio dos quais a vida adquire um sentido e por meio dos quais os jovens realizam sua juventude. Essa teia simbólica da sociabilidade pode ter seus fios tecidos a partir da arte (dança, pintura, música, teatro, etc.); da ciência (cursos universitários, grupos de estudo, etc.); da política (participação ativa em partidos, movimentos sociais, grupos ideológicos, etc.); e da religião (estudo do livro sagrado, grupo de jovens, grupos de oração, etc.). As possibilidades de agrupamento juvenil tendo por base uma forma simbólica são tantas quanto o/a investigador/a possa encontrar.

Em síntese, o que pretendemos com essa apresentação textual foi compartilhar uma proposta metodológica que nos abra caminhos para que possamos refletir formas de compreensão dos sentidos que permeiam a realidade do/a jovem religioso/a; sentido esse que parte do discurso (representação) da Igreja (religião). 


\section{Referências Bibliográficas}

ABRAMO, H. W. Cenas juvenis: punks e darks no espetáculo urbano. São Paulo: Scritta, 1994.

Considerações sobre a tematização social da juventude no Brasil. Revista Brasileira de Educação. ํo 5 e 6, mai/dez, 1997. p.25-36.

. O uso das noções de adolescência e juventude no contexto brasileiro. In: FREITAS, M. V. (Org) Juventude e adolescência no Brasil: referências conceituais. São Paulo: Ação Educativa, 2005.

. W.; BRANCO, P. P. M. (orgs). Retratos da juventude brasileira: análises de uma pesquisa nacional. São Paulo: Instituto Cidadania, Editora Fundação Perseu Abramo, 2005.

AITKEN, S. C. Geographies of young people: the morally contested spaces of identity. London: Routledge, 2001.

ALVES, R. O que é religião. Vol. 5. São Paulo: Brasiliense, 1981.

BERGER, P. L. A dessecularização do mundo: uma visão global. Religião e Sociedade, Rio de Janeiro, v.21, n.1, 2000. p.9-24.

BOURDIEU, P. A Economia das Trocas Simbólicas. São Paulo: Perspectiva, 1998. (1 ${ }^{\mathrm{a}}$ ed. original 1974$)$

A Economia das Trocas Linguísticas: o que falar quer dizer. 2 ed. $1^{\underline{a}}$ reimpr. São Paulo: Editora da Universidade de São Paulo, 2008. (1 ${ }^{a}$ ed. original 1982)

CARDOZO, C. E. Fé em Deus, pé na tábua - pertença religiosa e participação social das juventudes. In: OLIVEIRA, T. R. de; GONTIJO, C. R. B.; CASTRO, C. L. F. de; (Orgs). Políticas Públicas de Juventudes: contextos, percepções e desafios da prática. Barbacema: EdUEMG; Belo Horizonte: UFMG/FPP "Tancredo Neves", 2010. p.75-96.

Juventude, religião e Neoliberalismo. Disponível em: <http://www.casadajuventude.org.br> Acessado em: 15/05/2007.

CARDOSO, D da S. Underground Cristão: a construção geográfica de uma cena religiosa jovem alternativa. Porto Alegre: Liro, 2011.

. da S.; TURRA NETO, N. Juventude, cidade e território: esboço de uma Geografia das Juventudes. In: Seminário de Pesquisa Juventudes e Cidade, 1, 2011. (Digital) Anais... Juiz de Fora: Universidade Federal de Juiz de Fora, 2011. 
CARRANO, P. C. R. Os jovens e a cidade: identidades e práticas culturais em Angra de tantos reis e rainhas. Rio de Janeiro: Relume Dumará: FAPERJ, 2002.

CASSIRER, E. Filosofia das Formas Simbólicas I - A linguagem. São Paulo: Martins Fontes, 2001. (1 ${ }^{a}$ ed. original 1923)

. Las ciencias de la cultura. Trad. de Wenceslao Roces. 2 ed. México: FCE, 2005a. (1 $\stackrel{\text { a }}{ }$ ed. original 1942)

. Ensaio sobre o Homem: introdução a uma filosofia da cultura humana. São Paulo: Martins Fontes, 2005b. (1 ${ }^{\text {a }}$ ed. original 1944)

COSTA, M. R. da. Os Carecas de Cristo e as Tribos Urbanas do Underground Evangélico. In: PAIS, J. M.; BLASS, L. M. da S. (orgs). Tribos urbanas: produção artística e identidades. São Paulo: Annablume, 2004.

CRUZ, R. R. De máscaras, tribus y rituales: etnografias y otros textos nómadas. In: Emergencia de Culturas Juveniles: Estrategias del desencanto. Buenos Aires: Grupo Editorial Norma, 2000.

DWYER, C. Negotiating diasporic identities: young British South Asian Muslim women. Women's Studies International Forum, no 23, 2000. p.475-486.

DAYRELL, J. Juventude, grupos culturais e sociabilidade. Disponível em: $<$ www.fae.ufmg.br:8080/objuventude/acervo/texto\%SCABA2004.html> Acessado em: 04/12/2004.

. Um olhar sobre a juventude. In: DAYRELL, J. (Org). A música entra em cena: o rap e o funk na socialização da juventude. Belo Horizonte: Editora UFMG, 2005. p.21-44.

Juventude, grupos culturais e sociabilidade. Disponível em: <www.fae.ufmg.br:8080/objuventude/acervo/texto\%SCABA2004.html> Acesso em 04/04/2006.

ELIADE, M. Tratado de história das religiões. Lisboa: Cosmos, 1977.

FERNANDES, V. Filosofia, ética e educação na perspectiva de Ernst Cassirer. Tese (Doutorado em Educação). Faculdade de Educação da Universidade de São Paulo. São Paulo: 2006.

FERNANDES, D. Juventudes e Religião: contribuições a partir da Geografia da Religião. In: I Seminário de Pesquisa Juventudes e Cidade, 01, 2011. (Digital) Anais... Juiz de Fora: Universidade Federal de Juiz de Fora, 2011.

.; GIL FILHO, S. F. Geografia em Cassirer: perspectivas para Geografia da Religião. Revista GeoTextos. Salvador, v.07, ㄲo02, dez, 2011. 
.; TURRA NETO, N. Desvendando territórios: um olhar geográfico sobre a juventude evangélica. In: IV SEET - Seminário Estadual de Estudos Territoriais e II SNMT - Seminário Nacional sobre Múltiplas Territorialidades: Novos horizontes na Geografia: perspectivas de território e de territorialidade. (Digital) Anais... Francisco Beltrão, 2009.

; et. al. Grupo de discussão sobre juventude e cidade: uma experiência de pesquisa. In: Encontro Latino Americano de Geógrafos, 11, 2007. (Digital) Anais... Bogotá: Universidade Nacional de Colômbia, 2007.

GIL FILHO, S. F. Geografia Cultural: estrutura e primado das representações. In: Espaço e Cultura. Rio de Janeiro: (UERJ/NEPEC), v. 19-20, jan-dez, 2005. p.51-59.

Geografia da Religião: reconstruções teóricas sob o idealismo critico. In: KOZEL, S.; SILVA, J. da C.; GIL FILHO, S. F. (Orgs). Da Percepção e Cognição à Representação: reconstruções teóricas da Geografia Cultural e Humanista. São Paulo: Terceira Margem; Curitiba, NEER, 2007. p.207-222.

2008.

Espaço Sagrado: estudos em geografia da religião. Curitiba: Ibpex,

HOLLOWAY, J.; VALINS, O. Placing religion and spirituality in geography. Social and Cultural Geography, no1, 2002. p.5-10.

HOPKINS, P. E. Young people, masculinities, religion and race: new social geographies. Progress in Human Geography, no31(2), 2007. p.163-177.

et al. Mapping intergenerationalities: the formation of youthful religiosities. Transactions of the Institute of British Geographers, $\mathrm{n}-36$, 2011. p.314-327.

IBASE/POLIS. Juventude Brasileira e Democracia: participação, esferas e políticas públicas. Rio de Janeiro: Ibase/Polis, 2005. Disponível em: <http://www.polis.org.br/download/105.pdf> Acessado em: 06/08/2007.

IBGE - Instituto Brasileiro de Geografia e Estatística. Censo 2010. Disponível em:

$<$ http://www.sidra.ibge.gov.br/bda/tabela/listabl.asp?z=cd\&o=3\&i=P\&c=3107>

Acessado em: 15/07/2011.

KANT, I. Crítica da Razão Pura. Trad. Alex Marins. São Paulo: Martin Claret, 2001. (1르 ed. original 1787)

KONG, L. Mapping "new" geographies of religion: politics and poetics in modernity. Progress in Human Geography, no25, 2001. p.211-233.

MATTHEWS, H.; LIMB, M. Defining an agenda for the geography of children: review and prospect. Progress in Human Geography, no23, 1999. p.61-90. 
NOVAES, R. Juventude, percepções e comportamentos: a religião faz a diferença? In: ABRAMO, H. W.; BRANCO, P. P. M. (orgs). Retratos da juventude brasileira: análises de uma pesquisa nacional. São Paulo: Instituto Cidadania, Editora Fundação Perseu Abramo, 2005. p.263-290.

. Os jovens "sem religião": ventos secularizantes, "espírito de época" e novos sincretismos. Notas preliminares. Estudos avançados, №18 (52), set/dez, 2004. p.321-330.

ORTIZ, R. Introdução: a procura de uma sociologia da prática. In:

(org.) Pierre Bourdieu: sociologia. 2 ed. São Paulo: Ática, 1994. p.7-36.

PAIS, J. M. Culturas juvenis. $2^{\underline{a}}$ ed. Lisboa: Imprensa Nacional - Casa da moeda, 2003.

PELUSO, M. L.; TORMIM, C. V. Violência social, pobreza e identidade entre jovens no entorno do Distrito Federal. GEOUSP, São Paulo, n¹8, 2005. p.127137.

SIMMEL, G. Sociabilidade: um exemplo de sociologia pura ou formal. In: MORAIS FILHO, E. (Org.) Simmel. São Paulo: Ática, 1983. Ed., 2006.

Questões fundamentais da sociologia. Rio de Janeiro: Jorge Zahar

SKELTON, T.; VALENTINE, G. Cool places: geographies of youth culture. London: Routledge, 1998.

THIRY-CHERQUES, H.R. Pierre Bourdieu: a teoria na prática. RAP, Rio de Janeiro, 40(1), Jan/Fev. 2006. p. 27-55.

TURRA NETO, N. Enterrado Vivo: identidade punk em Londrina. São Paulo, Editora UNESP, 2004.

Múltiplas trajetórias juvenis em Guarapuava: territórios e redes de sociabilidade. 516 f. Tese (Doutorado em Geografia). Universidade Estadual Paulista, Faculdade de Ciências e Tecnologia, Presidente Prudente: 2008.

WACQUANT, L. Notas para esclarecer a noção de habitus. RBSE - Revista Brasileira de Ciências Sociais. ํㅡㅇ, 16, abril, 2007. p.5-11. 